\title{
EFETIVIDADE DE UM TREINAMENTO DE PROFESSORES \\ DE UMA ESCOLA DE EDUCAÇÃO ESPECIAL \\ USANDO OS PRINCÍPIOS DOS MÉTODOS \\ HANEN E V.O.E. - VEJA, OUÇA E ESPERE
}

\section{Effectiveness of teacher training in a school for students with special needs using Hanen method principles: See, Listen and Wait}

\author{
Maria de Fátima Dall’ Aqua ${ }^{(1)}$, Noemi Takiuchi ${ }^{(2)}$, Jaime Luiz Zorzi ${ }^{(3)}$
}

\section{RESUMO}

Objetivo: verificar a efetividade de um procedimento de capacitação para professores de alunos com necessidades especiais do município de Suzano, fazendo uso dos princípios dos métodos Hanen e Veja-Ouça-Espere (V.O.E), que seguem uma linha de intervenção interacionista. Métodos: o método Hanen foi criado em 1977 por Ayala Manolson, Fonoaudióloga no Canadá. Ele é dirigido a pais cujos filhos sejam portadores de um Retardo de Linguagem de qualquer etiologia. O método $\mathrm{V}$. O. E. (Veja, Ouça e Espere) é derivado do Programa Hanen e foi adaptado para a língua portuguesa por Rigoletto e Monteiro. Esse método propõe preparar as famílias para que possam estimular seus filhos por meio de interações sociais de maior eficácia. Neste trabalho usamos os princípios desses métodos adaptando-os ao contexto escolar. Quatro professores participaram dessa capacitação, a qual constou de três filmagens em sala de aula e dez sessões de orientações na Hora de Trabalho Pedagógico Compartilhado, sendo a primeira filmagem realizada antes da primeira sessão de orientação, a segunda realizada durante o treinamento e a última quando se encerrou a capacitação. A fonoaudióloga preencheu um protocolo específico de avaliação das orientações dadas após cada filmagem. Resultados: o número de comportamentos comunicativos dos professores aumentou significativamente após a capacitação, provavelmente devido às orientações dadas e às reflexões sobre as filmagens realizadas em sala de aula. Conclusões: a linha de intervenção proposta pelos métodos fez com que os professores mudassem sua maneira de trabalho em sala de aula, no sentido de perceberem o valor de atividades lúdicas e a efetiva estimulação de fala e linguagem que as mesmas proporcionam.

DESCRITORES: Capacitação; Educação Especial; Intervenção Precoce (Educação)

\section{INTRODUÇÃO}

O relacionamento entre professores e alunos é um tema importante a ser considerado, não só

(1) Fonoaudióloga da Prefeitura Municipal de Suzano; Especialista em Audiologia e em Linguagem.

(2) Fonoaudióloga Professora Assistente do Curso de Fonoaudiologia da Faculdade de Ciências Médicas da Santa Casa de São Paulo; Doutora em Semiótica e Lingüística Geral pela Faculdade de Filosofia, Letras e Ciências Humanas da Universidade de São Paulo.

(3) Fonoaudiólogo; Diretor do Centro de Especialização em Fonoaudiologia Clínica; Doutor em Educação pela Universidade Estadual de Campinas. quando se fala em aprendizagem, mas também quando se pensa em estimulação de linguagem. O trabalho com profissionais que lidam diretamente com as crianças, independentemente da formação acadêmica que possuam, tem se mostrado muito proveitoso. Embora palestras para grande número de indivíduos seja uma estratégia possível (e às vezes única) de orientação, a experiência tem demonstrado que o trabalho em pequenos grupos, formados a partir de interesses comuns tem permitido melhor aproveitamento dos conteúdos abordados ${ }^{1,2}$.

A obtenção de conhecimentos sobre os distúrbios da comunicação pode transformar professores, 
e tantos outros, em agentes multiplicadores, favorecendo assim, a detecção e o encaminhamento precoce de problemas na comunicação. Informações a respeito da aquisição e das alterações da linguagem infantil devem estar ao alcance de todos os profissionais que trabalham com crianças a fim de que estes possam orientar e encaminhar as famílias cujos filhos, que por algum motivo, não estejam conseguindo evoluir satisfatoriamente ${ }^{3-5}$.

As estratégias utilizadas no trabalho educativo com os professores devem permitir não só a construção de novos conhecimentos, mas também a sensibilização desses profissionais para os assuntos que serão abordados. A utilização de técnicas participativas facilita essa sensibilização, permitindo um aprendizado útil e consciente e não apenas a retenção momentânea das informações transmitidas. O trabalho de orientação aos professores também encontra respaldo na literatura, demonstrando a importância da orientação aos professores quanto ao material usado em sala de aula e ao método de trabalho, o qual irá variar de escola para escola 6,7 .

Deve-se estar atento para que, de fato, ocorra um ajuste entre a proposta da escola e as características da criança, o objetivo da escola e da educação, num processo de aprendizagem, é tornar o individuo independente, desfrutando da interação com seus semelhantes, com autocontrole, desenvolvendo habilidades práticas, ampliando seus conhecimentos de mundo e de aspectos culturais. A escola também pode ter um papel fundamental no processo de comunicação, na medida em que se torne fonte de informação estimulando, assim, o desenvolvimento da linguagem. Para tanto, é necessário que o corpo docente conheça o processo de aquisição e desenvolvimento de linguagem, bem como os distúrbios ligados à comunicação ${ }^{8-10}$.

Por meio da comunicação os seres humanos são capazes de entrar em contato e interagir com o outro, trocando experiências. Esse processo se aprimora à medida que a criança busca uma interação mais efetiva e prazerosa com o meio, desenvolvendo cada vez mais a sua linguagem ${ }^{10,11}$.

A comunicação é a capacidade de transmitir informações, por meio de códigos e diferentes sistemas, regidas por regras gerais, a fim de que o sujeito possa integrar-se à sociedade. A fala associada a gestos, expressões faciais e corporais permitem a interação com as outras pessoas, comunidades e culturas, formando laços sociais, caracterizando a condição humana ${ }^{12,13}$.

Pensando no favorecimento do processo de integração, cabe ao fonoaudiólogo fornecer assistência e suporte para os professores nos assuntos de sua competência, proporcionando, por meio de orientações e de planejamentos direcionados, melhores condições para que as crianças que forem integradas, tenham possibilidades de acompanhar as atividades propostas na classe comum ${ }^{6,14,15}$.

Cada vez mais se tem apontado para práticas fonoaudiológicas educacionais que, além de detectar alterações, possam formar educadores e pais para lidar com elas, buscando promover atividades que favoreçam a potencialidade dos alunos ao máximo ${ }^{16,17}$.

Dentro desta proposta de atuação, o método Hanen usado neste estudo e que foi criado em 1977 por Ayala Manolson, Fonoaudióloga no Canadá, é um programa que enfoca o interesse da criança e é dirigido à família da mesma, onde o papel da fonoaudióloga é ensinar os pais a serem facilitadores da linguagem da criança. Esse método foi adaptado para a língua portuguesa por Rigoletto e Monteiro e recebeu o nome de método $V$. O. E. cuja as siglas significam Veja, Ouça e Espere 18,19.

Os participantes do programa recebem, além de um apoio individual através da orientação de especialistas, o suporte fundamental do grupo de pais ao qual pertencem, considerando que eles receberão informações individuais e específicas por parte do profissional e das experiências vivenciadas por outras famílias ou professores. O programa não lida com idades cronológicas específicas, mas com níveis de desenvolvimento: nível global atingido por cada criança e níveis específicos obtidos em cada área de desenvolvimento (comunicação, linguagem oral, linguagem escrita: "leitura" ou expressão gráfica, cognição, sócio-afetiva, psicológica, de autonomia, de autoconfiança e auto-estima, de jogo físico, simbólico, de regra, dentre outros). Este fato, aparentemente simples, por si só desmistifica a noção de atraso em relação à norma, valorizando a passagem de fases sucessivas bem sucedidas e assinaladas progressivamente de forma a solidificar os conhecimentos assim adquiridos, e a memorizá-los com maior facilidade. Dessa forma, os pais têm a oportunidade de descobrir quais estratégias ajudam a criança a aprender e quais não ajudam ${ }^{19,20}$.

Além do vínculo afetivo entre pais e crianças ser incomparavelmente mais forte do que o vínculo terapeuta - criança, também as oportunidades que surgem em casa são infinitamente mais propícias ao desenvolvimento da comunicação do que aquelas que aparecem dentro de um consultório. Por esta razão, o terapeuta Hanen não atua diretamente com a criança, assumindo o papel de facilitador da comunicação entre pais e filhos. Ele ensina aos pais como tirar proveito máximo das situações diárias fazendo com que estas se tornem uma fonte prazerosa e constante de estimulação da linguagem, sendo assim, esse trabalho exige um comprometimento efetivo da família ${ }^{21}$. 
Pesquisas realizadas apontam que apenas um terço dos pais de pacientes que passam por uma primeira avaliação chegam ao fim do programa, sendo que o fator decisivo para que eles concluam ou não o Hanen é o nível de escolaridade que apresentam ${ }^{22,23}$.

O uso de registros em vídeo é a principal ferramenta dos métodos, pois é por meio dele que os pais avaliam seu próprio comportamento e percebem as reações da criança. Desta forma, a partir da análise das interações, eles podem ajustar posturas e atitudes, melhorando, conseqüentemente, a comunicação com seus filhos.

Além de aprender com os filmes, os pais podem notar as mudanças do próprio comportamento e o progresso da criança na seqüência de registros. A importância e a grande vantagem dos pais aprenderem a avaliar os próprios filhos é que eles passam a ajustar seus comportamentos e expectativas a um patamar mais real e efetivo de comunicação. Os pais também recebem esclarecimentos sobre o processo de desenvolvimento da linguagem, levando em conta que esse desenvolvimento iniciasse ao nascer, onde o bebê começa a estabelecer diálogos com sua mãe: ela brinca com o bebê, ele gorjeia, ela brinca de novo, ele sorri, e assim esse diálogo prossegue. Deste modo, a comunicação torna-se recíproca, com idas e vindas, constituindo as bases para as habilidades futuras da conversação ${ }^{24,25}$.

Porém, com a criança que apresente limitações no desenvolvimento à trajetória tenderá a ser diferente, suas estratégias de comunicação podem ser pouco eficientes e, principalmente, processadas muito lentamente. Neste caso, o adulto não percebe as tentativas da criança e começa a tomar seu espaço no diálogo, aumentando a fala. Conseqüentemente, quanto mais o adulto fala, mais inibe a resposta da criança. A relação dialógica, marcada pela reciprocidade da linguagem, desaparece. A criança passa a ser somente um receptor de linguagem e não um produtor. Porém, tal "bombardeio verbal" pode não ter efeitos, pela ausência da reciprocidade. Daí a necessidade de se considerar a trilogia "Observar", "Esperar" e "Escutar" proposta pelo método V.O.E.

A falta de uma sintonia mais afinada pode ser observada em muitos registros de vídeo. É comum constatar que poucos pais mantêm os olhos à altura do olhar de seus filhos. Esta é uma regra muito elementar de comunicação, com efeitos sensíveis sobre a qualidade da interação. Outra estratégia, também simples e que produz bons resultados, é a da imitação. Ao ser imitada, a criança tende a se ligar mais fortemente ao interlocutor na medida em que sente que ele se interessa por seu modo de agir $8,18,22$.
Ao participarem desta capacitação os pais aprendem a aplicar os princípios dos métodos Hanen e V.O.E. no brincar, nas músicas, em atividades de arte e no manuseio de livros. Estas formas de estimulação são analisadas e vivenciadas durante os encontros de grupos. Pais que passam pelo programa tendem a adquirir mais confiança e habilidade para estimular a linguagem de seus filhos e, conseqüentemente, se tornam menos ansiosos. Esta condição permite uma melhora da interação levando a um maior equilíbrio emocional, além de estimular o desenvolvimento intelectual e social, de um modo geral ${ }^{18}$.

Porém, preparar o adulto para tal aprendizado é uma tarefa desafiadora. Aprender é um processo ativo. Assim sendo, simplesmente ter contato com um conhecimento não garante a sua compreensão e a mudança de comportamentos. Há de se considerar os aspectos cognitivos e afetivos da aprendizagem e eles estão presentes quando o conteúdo é significativo e útil. Dessa forma é preciso motivar as pessoas para o aprendizado, provendo-as de informações e de oportunidades para experimentar novos modos de agir. Devem ser criados meios que facilitem a ação e a análise destes novos comportamentos. Neste sentido, fornecer informações e dar devolutivas constantes são estratégias fundamentais para que as pessoas reconheçam o quanto aprenderam e transformaram suas ações ${ }^{18}$.

Desta forma, o presente estudo teve como objetivo verificar a efetividade de um programa de orientação a professores de alunos com necessidades especiais, elaborado a partir de princípios dos Programas Hanen e V. O. E. Usando recursos audiovisuais como ferramenta para facilitar à análise das interações, buscando otimizar o comportamento comunicativo dos professores com seus alunos.

\section{MÉTODOS}

Foi obtida autorização da escola, dos pais e dos professores, por meio da assinatura do termo de Consentimento livre e Esclarecido.

Participaram deste estudo quatro professoras com idades entre 26 e 42 anos e 15 alunos, de ambos os sexos, com idades entre seis e 13 anos, cursando diferentes módulos de Educação Infantil em uma escola de Educação Especial da Rede Municipal de Suzano. O critério para inclusão na amostra foi o maior número de professores concentrados no horário de HTPC (Hora de Trabalho Pedagógico Compartilhado) e a disponibilidade dos mesmos em participar desta capacitação. Os encontros com os professores aconteceram na sala dos professores e as filmagens nas salas de aulas. 
A fonoaudióloga elaborou um protocolo a partir das orientações dadas pelos métodos (Figura 1), que foi respondido pela própria profissional após cada filmagem, buscando verificar a ocorrência de mudanças de posturas e atitudes comunicativas dos professores.

A capacitação destes professores de acordo com as orientações dos métodos Hanen / V.O.E., foi realizada por meio de dez sessões, com a apresentação das interações professor/aluno registradas em vídeo, durante o período 6 meses.

As sessões de orientação tiveram periodicidade semanal com duração de uma hora cada. Foram feitas três filmagens nas salas de aulas dos professores, uma antes do início da capacitação, outra na metade do processo e a última no término, sendo que cada um dos quatro professores interagiu com seu grupo de alunos, contendo de três a quatro participantes cada um.

Foi utilizada para este estudo uma filmadora marca Panasonic modelo RJ 67, televisão, vídeo cassete, apostilas para cada sessão de orientação, fita de vídeo com o curso "Estimulação Precoce em Comunicação e Linguagem Segundo o Modelo V.O.E." e uma caixa de brinquedos contendo miniaturas de objetos da casa, animais e bonecos, canecas de encaixe, recipientes com tampas, objetos sem uso definido (pano e blocos de plástico) e blocos de madeira para jogos de construção.

Antes de iniciar as filmagens os professores receberam a orientação de que deveriam brincar com seus alunos, sendo oferecida pela pesquisadora uma caixa de brinquedos.

A Figura 1 é o modelo de protocolo preenchido pela pesquisadora, no qual a questão 1 refere-se à postura comunicativa do professor, as questões de 2 a 14 são relativas às atitudes comunicativas orientadas pelos métodos e a questão 15 registra a ocorrência do jogo simbólico na interação. A resposta da questão 1 foi classificada subjetivamente em: apressado, salvador, professor, cansado ou afinado e as respostas às questões de 2 a 15 foram classificadas em: sempre, freqüentemente, às vezes e nunca.

A Figura 2 descreve as orientações realizadas em cada sessão da capacitação.

O presente estudo foi apresentado ao Comitê de Ética em Pesquisa do CEFAC -Saúde e Educação, tendo sido aprovado sob número 037/05.

Os resultados foram analisados estatisticamente por meio de comparação das respostas dos protocolos específicos, antes e após o treinamento e apresentados na forma de Quadros e Tabelas com números absolutos e percentuais. Foi aplicado o teste paramétrico de igualdade de duas proporções para comparação das proporções de respostas das variáveis estudadas. O nível considerado estatisticamente significante foi o de $5 \%$ (p-valor $\leq 0.05$ ).

Por meio do teste paramétrico de igualdade de duas proporções de respostas das variáveis estudadas, as Tabelas de 1 a 5 comparam as respostas antes e após a intervenção. Nas Tabelas de 1 a 5 , os resultados considerados estatísticamente significativos apresentaram $p=0,028$ enquanto que um dos $p$-valores $(p=0,102)$, por estar próximo do limite de aceitação, foi considerado com tendência a ser significativo.

\section{RESULTADOS}

Segundo a análise dos protocolos preenchidos após cada filmagem pela fonoaudióloga, observase uma tendência à mudança de postura do professor durante a interação com seus alunos antes e após a capacitação. Este fato fica mais evidenciado na Tabela 1 (aumento de freqüência das atitudes comunicativas), nos resultados descritos nas Tabelas 2, 3, 4 (nomeação de objetos, nomeação de ações e acréscimo de linguagem, respectivamente) e na Tabela 5 (experiência e aumento na ocorrência de jogos de caráter simbólico).

A Tabela 1 demonstra que existiu diferença significativa no que diz respeito à postura do professor ("antes" e "depois"), a qual se tornou "afinada" após a intervenção, confirmando a eficácia do processo de capacitação.

A Figura 3 demonstra aumento da resposta "freqüentemente" antes e após a intervenção, nas questões de número 2 a 15, apresentando uma variação de 23 para 31, o que corresponde a $41 \%$ antes da intervenção para $55 \%$ após a mesma.

\section{DISCUSSÃO}

A importância da atuação da Fonoaudiologia na área da Educação está crescendo cada vez mais, tanto em instituições privadas como públicas. Por outro lado, o trabalho com profissionais, como os professores, que lidam diretamente com as crianças, tem se revelado muito promissor e proveitoso. A experiência tem mostrado que trabalho com grupos, formados a partir de desafios e interesses comuns, tem permitido melhor aproveitamento dos conteúdos apresentados ${ }^{2}$. Todos os aspectos da linguagem (fonético - fonológico, sintático, semântico e pragmático) podem ser trabalhados em situações naturais, contextualizadas, englobando habilidades como as iniciativas de comunicação, a atenção conjunta, o contato ocular, a atividade simbólica e o desenvolvimento cognitivo, direcionados para a evolução da comunicação em geral e da linguagem em particular ${ }^{26}$. 


\section{Protocolo de observação das filmagens}

1. Atitude do professor (a):

Apressado ( ) Salvador ( ) Professor ( ) Cansado ( ) Afinado ( )

2. A comunicação ocorre face a face com o professor (a):

Sempre ( ) Freqüentemente ( ) Às vezes ( ) Nunca ( )

3. O professor (a) deixa o aluno(a) liderar:

Sempre ( ) Freqüentemente ( ) Às vezes ( ) Nunca ( )

4. O professor (a) deixa o aluno (a) iniciar a comunicação:

Sempre ( ) Freqüentemente ( ) Às vezes ( ) Nunca ( )

5. O professor (a) observa, espera e escuta:
Sempre ( )
Freqüentemente ( )
Às vezes ( ) Nunca ( )

6. O professor (a) nomeia os objetos:

Sempre ( ) Freqüentemente ( ) Às vezes ( ) Nunca ( )

7. O professor (a) nomeia a ação:

Sempre ( ) Freqüentemente ( ) Às vezes ( ) Nunca ( )

8. O professor (a) usa fala infantilizada:

Sempre ( ) Freqüentemente ( ) Às vezes ( ) Nunca ( )

9. O professor (a) demonstra entusiasmo:

Sempre ( ) Freqüentemente ( ) Às vezes ( ) Nunca ( )

10. O professor (a) imita os sons ou ações:

Sempre ( ) Freqüentemente ( ) Às vezes ( ) Nunca ( )

11. O professor (a) interpreta o sentido dos sons, fala ou gestos feito pelos alunos (as):

Sempre ( ) Freqüentemente ( ) Às vezes ( ) Nunca ( )

12. O professor (a) repete vocábulos:

Sempre ( ) Freqüentemente ( ) Às vezes ( ) Nunca ( )

13. O professor (a) procura acrescentar linguagem e experiência:

Sempre ( ) Freqüentemente ( ) Às vezes ( ) Nunca ( )

14. O professor (a) usa boas perguntas:

Sempre ( ) Freqüentemente ( ) Às vezes ( ) Nunca ( )

15. Foi observado jogo simbólico:

Sempre ( ) Freqüentemente ( ) Às vezes ( ) Nunca ( )

Figura 1 - Protocolo preenchido após cada filmagem 


\begin{tabular}{|c|c|}
\hline Sessões & Orientações e Discussões \\
\hline 1 & $\begin{array}{l}\square \text { Fatores determinantes do desenvolvimento da comunicação infantil } \\
\square \text { Caracterização do grau de desenvolvimento da linguagem dos alunos } \\
\square \text { Papéis vividos pelos professores e pelos alunos } \\
\square \text { Exibição e discussão da filmagem da sala } 1 \text { - primeira filmagem }\end{array}$ \\
\hline 2 & $\begin{array}{l}\square \text { Retomada do que foi abordado no encontro anterior } \\
\square \text { Importância da comunicação face a face } \\
\square \text { Esperar, escutar, observar e deixar o aluno liderar } \\
\square \text { Oferecer brinquedos que estimulem a curiosidade ou a motivação da criança } \\
\square \text { Evitar antecipar os desejos da criança } \\
\square \text { Transformar as situações do dia a dia em atividades interessantes } \\
\square \text { Exibição e discussão da filmagem da sala } 2 \text { - primeira filmagem }\end{array}$ \\
\hline 3 & $\begin{array}{l}\square \text { Retomada do que foi abordado nos encontros anteriores } \\
\square \text { Adaptar para compartilhar os momentos } \\
\square \text { Estimular a participação alternada } \\
\square \text { Utilizar a rotina para estimular a conversação } \\
\square \text { Atitudes que ajudam os alunos a progredirem } \\
\square \text { Acrescentar linguagem e experiência } \\
\square \text { Dar ênfase nas informações } \\
\square \text { Exibição e discussão da filmagem da sala 3 - primeira filmagem }\end{array}$ \\
\hline 4 & $\begin{array}{l}\square \text { Retomada do que foi abordado nos encontros anteriores } \\
\square \text { Análise dos níveis, aspectos da linguagem e perfil comunicativo dos alunos } \\
\square \text { Análise dos papéis vividos pelos professores } \\
\square \text { Exibição e discussão da filmagem da sala } 4 \text { - primeira filmagem }\end{array}$ \\
\hline 5 & $\begin{array}{l}\square \text { Retomada do que foi abordado nos encontros anteriores } \\
\square \text { Avaliação dos progressos dos trabalho } \\
\square \text { Exibição e discussão da filmagem da sala } 1 \text { - segunda filmagem }\end{array}$ \\
\hline 6 & $\begin{array}{l}\square \text { Retomada do que foi abordado nos encontros anteriores } \\
\square \text { Boas perguntas e perguntas ruins } \\
\square \text { Exploração das atividades lúdicas } \\
\square \text { Exibição e discussão da filmagem da sala } 2 \text { - segunda filmagem }\end{array}$ \\
\hline 7 & $\begin{array}{l}\square \text { Retomada do que foi abordado nos encontros anteriores } \\
\square \text { Sugestões de jogos e brincadeiras } \\
\square \text { Sugestões para atividades musicais } \\
\square \text { Aspectos a serem valorizados em todas as atividades } \\
\square \text { Balanço das atividades realizadas } \\
\square \text { Exibição e discussão da filmagem da sala } 3 \text { - segunda filmagem }\end{array}$ \\
\hline 8 & $\begin{array}{l}\square \text { Retomada do que foi abordado nos encontros anteriores } \\
\square \text { Segunda avaliação do trabalho } \\
\square \text { Jogos com e sem brinquedos } \\
\square \text { Atividades cotidianas } \\
\square \text { O uso da musica na estimulação de fala e linguagem } \\
\square \text { Exibição e discussão da filmagem da sala } 4 \text { - segunda filmagem }\end{array}$ \\
\hline 9 & $\begin{array}{l}\square \text { Retomada do que foi abordado nos encontros anteriores } \\
\square \text { Aspectos valorizados nas orientações } \\
\square \text { Atitudes facilitadoras na comunicação } \\
\square \text { Exibição e discussão do vídeo sobre o método V. O.E. - Pró Fono }\end{array}$ \\
\hline 10 & $\begin{array}{l}\square \text { Retomada do que foi abordado nos encontros com uso de apostila } \\
\square \text { Exibição e discussão da filmagem das sala } 1,2,3 \text { e } 4 \text { - terceira filmagem } \\
\square \text { Avaliação feita pelos professores sobre os métodos }\end{array}$ \\
\hline
\end{tabular}

Figura 2 - Descrição dos temas abordados nas orientações realizadas em cada sessão da capacitação 
Tabela 1 - Comparação das respostas da questão 1 (Postura do professor), antes e após a intervenção

\begin{tabular}{cccccc}
\hline \multirow{2}{*}{1} & \multicolumn{2}{c}{ Antes } & \multicolumn{2}{c}{ Depois } & \multirow{2}{*}{ p-valor } \\
\cline { 2 - 5 } & Qtde & $\%$ & Qtde & $\%$ & \\
\hline Afinado & 0 & $0,0 \%$ & 3 & $75,0 \%$ & \multirow{2}{*}{$0,028^{\star}$} \\
Professor & 4 & $100,0 \%$ & 1 & $25,0 \%$ & \\
\hline
\end{tabular}

Tabela 2 - Comparação das respostas da questão 6 (O professor(a) nomeia os objetos), antes e após a intervenção

\begin{tabular}{cccccc}
\hline \multirow{2}{*}{6} & \multicolumn{2}{c}{ Antes } & \multicolumn{2}{c}{ Depois } & \multirow{2}{*}{ p-valor } \\
\cline { 2 - 5 } & Qtde & $\%$ & Qtde & $\%$ & \\
\hline Às Vezes & 2 & $50,0 \%$ & 0 & $0,0 \%$ & $0,102 \#$ \\
Freqüentemente & 2 & $50,0 \%$ & 3 & $75,0 \%$ & 0,465 \\
Sempre & 0 & $0,0 \%$ & 1 & $25,0 \%$ & 0,285 \\
\hline
\end{tabular}

Tabela 3 - Comparação das respostas da questão 7 (O professor(a) nomeia a ação), antes e após a intervenção

\begin{tabular}{cccccc}
\hline \multirow{2}{*}{7} & \multicolumn{2}{c}{ Antes } & \multicolumn{2}{c}{ Depois } & \multirow{2}{*}{ p-valor } \\
\cline { 2 - 5 } & Qtde & $\%$ & Qtde & $\%$ & \\
\hline Freqüentemente & 0 & $0,0 \%$ & 2 & $50,0 \%$ & $0,102 \#$ \\
Nunca & 2 & $50,0 \%$ & 1 & $25,0 \%$ & 0,465 \\
Sempre & 2 & $50,0 \%$ & 1 & $25,0 \%$ & 0,465 \\
\hline
\end{tabular}

Tabela 4 - Comparação das respostas da questão 13 (O professor(a) procura acrescentar linguagem e experiência), antes e após a intervenção

\begin{tabular}{cccccc}
\hline \multirow{2}{*}{13} & \multicolumn{2}{c}{ Antes } & \multicolumn{2}{c}{ Depois } & \multirow{2}{*}{ p-valor } \\
\cline { 2 - 5 } & Qtde & $\%$ & Qtde & $\%$ & \\
\hline As Vezes & 3 & $75,0 \%$ & 2 & $50,0 \%$ & 0,465 \\
Freqüentemente & 0 & $0,0 \%$ & 2 & $50,0 \%$ & $0,102 \#$ \\
Nunca & 1 & $25,0 \%$ & 0 & $0,0 \%$ & 0,285 \\
\hline
\end{tabular}

Tabela 5 - Comparação das respostas da questão 15 (Foi observado jogo simbólico), antes e após a intervenção

\begin{tabular}{cccccc}
\hline \multirow{2}{*}{15} & \multicolumn{2}{c}{ Antes } & \multicolumn{2}{c}{ Depois } & \multirow{2}{*}{ p-valor } \\
\cline { 2 - 5 } & Qtde & $\%$ & Qtde & $\%$ & \\
\hline As Vezes & 2 & $50,0 \%$ & 0 & $0,0 \%$ & $0,102 \#$ \\
Freqüentemente & 0 & $0,0 \%$ & 3 & $75,0 \%$ & $0,028^{*}$ \\
Nunca & 2 & $50,0 \%$ & 1 & $25,0 \%$ & 0,465 \\
\hline
\end{tabular}




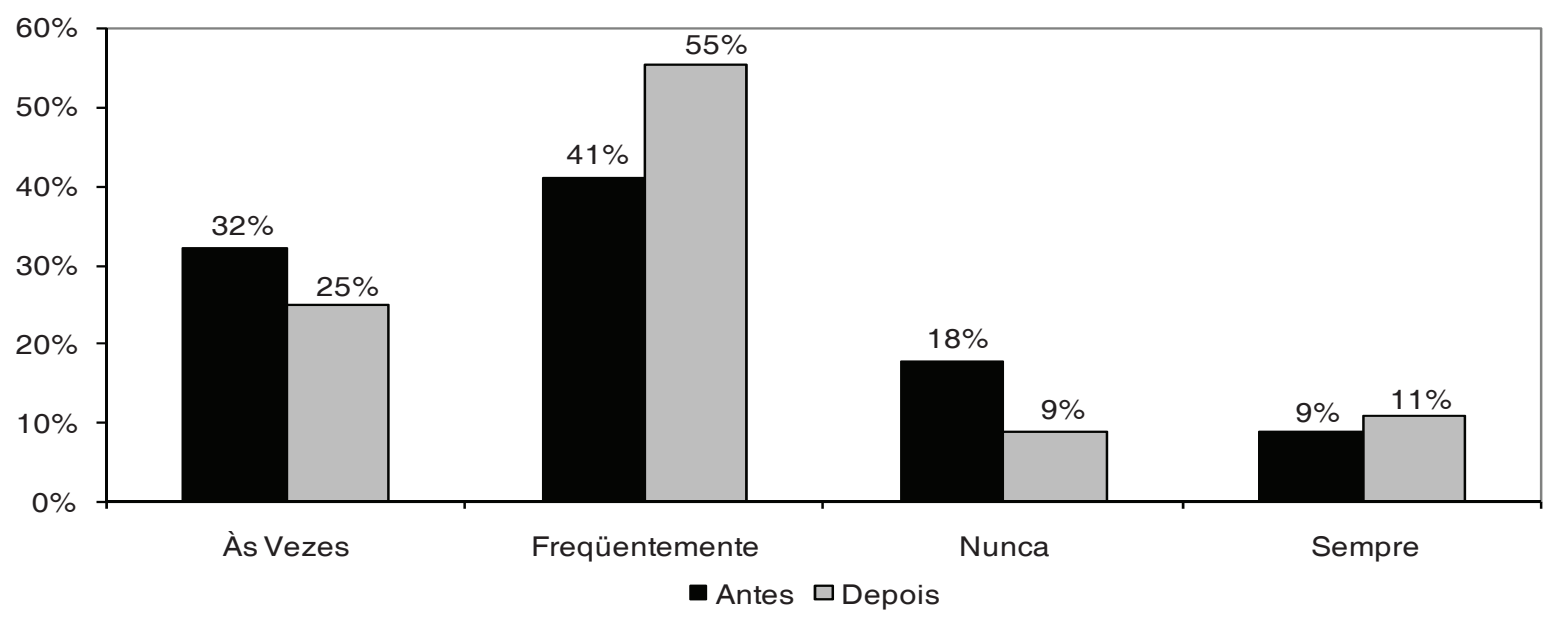

Figura 3 - Porcentagem dos resultados obtidos por meio do protocolo antes e após a intervenção

Os métodos Hanen e V.O.E. têm como objetivo orientar famílias com crianças que possuam atrasos no desenvolvimento da fala e linguagem ${ }^{18,20}$. Neste trabalho foi proposta uma adaptação desses métodos, voltando-os para o ambiente escolar, tendo como foco o professor, na literatura não foi encontrado trabalhos desta natureza.

Os resultados obtidos a partir deste programa de treinamento de professores dependeram nitidamente de fatores subjetivos, ligados ao envolvimento e interesse de cada um deles frente à proposta. Alguns foram mais abertos e disponíveis, procurando mudanças ou a aquisição de novas posturas. Outros foram mais fechados, pouco suscetíveis a qualquer modificação, o que também é descrito na literatura ${ }^{5,16}$.

Observou-se uma tendência bastante diretiva por parte dos professores na primeira filmagem, na qual os alunos foram sistematicamente direcionados com ordens e perguntas. Não foi dado a eles nem o tempo, nem a liberdade que necessitavam para uma exploração espontânea dos objetos oferecidos. Na terceira filmagem, ao deixarem os alunos liderarem, a comunicação com eles se tornou mais efetiva. Para que isso acontecesse foi necessário que os professores adaptassem seu comportamento comunicativo para partilhar esse momento com os alunos, proporcionando uma postura comunicativa mais afinada com o interesse dos alunos. Mudanças desta natureza também são verificadas quando os pais participam do programa Hanen ${ }^{18-20}$.

Outra importante mudança de postura comunicativa foi uma preocupação dos professores, durante a terceira filmagem, em adotar uma posição face a face sistemática com os alunos, de forma que seus olhos ficassem à altura dos olhos das crianças. Nas primeiras filmagens, apenas dois professores ado- taram esta postura que facilita a comunicação, tornando as crianças mais atentas e comunicativas.

Verifica-se que ocorreu uma tendência de aumento no número de atitudes comunicativas dos professores em relação aos seus alunos. Conseqüentemente, diminuíram as atitudes diretivas controladoras sendo que os professores deixaram os alunos liderarem, assim como estimularam o interesse dos mesmos. O resultado pode ser considerado como efetivo na medida em que ocorreram mudanças nas intervenções feitas por parte dos professores com seus alunos em sala de aula, tendo como foco a melhora da qualidade comunicativa entre ambos.

Os resultados também mostraram aumento na ocorrência de jogo simbólico. Na primeira filmagem apenas em um grupo foi notada a presença de brincadeira simbólica. Porém, na terceira gravação, este comportamento foi observado em três grupos. Provavelmente, o aumento da interatividade das crianças e da atenção aos comportamentos dos outros pode ter contribuído para uma maior ocorrência desta conduta representativa, considerada de grande importância para o desenvolvimento da linguagem e do simbolismo de modo geral ${ }^{5}$.

A análise das filmagens realizadas foi essencial para propiciar uma reflexão crítica e construtiva sobre as posturas e atos comunicativos, sendo esta a principal ferramenta da metodologia adotada. A partir da observação dos próprios comportamentos, os professores tiveram a oportunidade de avaliar suas ações e constatar as reações por parte dos alunos. Observou-se que este procedimento permite que o professor faça ajustes em suas posturas e atitudes, o que pode levar a uma comunicação mais satisfatória com os alunos. No trabalho com o treinamento de pais a literatura aponta resultados semelhantes ${ }^{21}$. 
Durante as sessões de orientação, os professores aprenderam a analisar os próprios filmes e também os de seus colegas. Juntamente com a pesquisadora, ao assistirem aos filmes, observando erros e acertos, eles tiveram a oportunidade de traçarem objetivos. Deve ser ressaltado que, sistematicamente, aspectos positivos das interações foram sendo apontados pela pesquisadora. Além de aprender por meio das filmagens, os professores puderam perceber a mudança de comportamentos e, conseqüentemente, o progresso dos alunos na seqüência dos registros.

Esse trabalho mostra que cabe ao fonoaudiólogo, dentro da escola, preparar os professores para que logrem por uma melhor estimulação de fala e linguagem, propiciando um conhecimento apropriado de aspectos relativos ao desenvolvimento de linguagem dos alunos ${ }^{18}$.

A importância de uma orientação planejada ficou evidente neste trabalho. O resultado foi uma tendência de modificação no comportamento comunicativo dos professores, favorecendo a comunicação com os alunos. Embora esta seja uma experiência com uma série de restrições que impedem uma análise estatística mais ampla, existem indicativos qualitativos que apontam para sua efetividade e para a necessidade de trabalhos mais extensos.

\section{CONCLUSÃO}

De acordo com os resultados obtidos por meio da análise do Protocolo de Observação das Filmagens, elaborado pela própria fonoaudióloga que propôs este trabalho, pautado nas orientações dadas pelos métodos aplicado antes e após a intervenção, verificou-se mudanças qualitativas nas atitudes dos professores em sala de aula, passando da postura de "professor" para uma postura "afinada", ou seja, em sintonia com o aluno.

Foi também encontrado aumento de atitudes comunicativas como: nomeação de ações e objetos, acréscimo de linguagem e experiências, além do incremento da ocorrência de jogo simbólico.

O presente estudo evidenciou a efetividade de um programa de treinamento de professores de alunos com necessidades especiais, a partir dos princípios dos métodos Hanen e V.O.E. Dessa forma mostrou que é possível o fonoaudiólogo, dentro da escola, colaborar com a formação dos professores, na medida em que pode proporcionar um conhecimento mais apropriado de aspectos relativos ao desenvolvimento de linguagem, dando diretrizes concretas para que os professores estimulem a fala e a linguagem de seus alunos.

\section{ABSTRACT}

Purpose: to check the effectiveness of a training program for teachers of students with special education needs based on Hanen and S.W.L. (See, Wait and Listen) Programs, both of them proposing an interacionist intervention line. Methods: Hanen Program was created in 1977 by Ayala Manolson, a Speech Language Pathologist in Canada. It is designed for parents of children diagnosed with limited communication ability. The S.W.L Program was derived from the Hanen Program and adapted to the Portuguese language by Rigoletto and Monteiro. Its purpose is to prepare families to stimulate their children by more effective social interactions. For the present paper, the principles of both Programs were adapted to the school context. Four teachers took part in this program, which consisted of ten guidance sessions and three video recordings of the teachers and their groups. Each teacher was recoded on film for three times: first before the first guidance session; second during the training; and third after the guidance sessions were over. After each video recording, the speech language pathologist in charge filled out a specific form in order to assess the effectiveness of the given guidance. Results: the number of communicative behaviors concerning the teachers increased significantly after developing the course. This was probably due to the given guidance and the reflections after watching the videos, when the teachers could evaluate their students and their own communication behavior, and because of the opportunity for sharing experiences with other teachers. Conclusions: the intervention proposed by the Programs caused some teachers to change their way of working in classroom, as they noted the value achieved in playful activities and speech and language stimulation that thy propitiate.

KEYWORDS: Training; Education, Special; Early Intervention (Education) 


\section{REFERÊNCIAS}

1. Silva DA. Treinamento de professores para o desenvolvimento da educação social e afetiva: análise comparativa com base nos dados do TRF e do YSR [dissertação]. São Paulo (SP): Universidade Federal de São Paulo; 2003. p.10-22.

2. Cavalheiro MTP. Trajetória e possibilidades de atuação do fonoaudiólogo na escola. In: Lagrotta MGM, Ribeiro CPHA. A fonoaudiologia nas instituições. São Paulo: Lovise; 1997. p. 81-5.

3. Paixão EC, Sanches C, Ribeiro-César C PHA, Lagrotta MGM. Magistério, pedagogia e fonoaudiologia: uma integração premente. In: Lagrotta MGM, Ribeiro CPHA. A fonoaudiologia nas instituições. São Paulo: Lovise; 1997. p.89-92.

4. Largo M, Zini TC, Ferreira VJA. A narrativa da criança e do adolescente na deficiência mental. Rev Cons Fed Fonoaudiol. 2003; 2(3):12-4.

5. Zorzi JL. Aspectos básicos para compreensão, diagnóstico e prevenção dos distúrbios de linguagem na infância. Rev CEFAC. 2000; 2(1):11-5.

6. Martins GAH. Refletindo sobre a atuação do fonoaudiólogo na educação especial. In: Giroto CRM. Perceptivas atuais da fonoaudiologia na escola. São Paulo: Plexus; 2001. p. 111-9.

7. Kyrillos LCR, Martins KC, Ferreira PEA. Fonoaudiologia e escola: a aprendizagem de uma visão preventiva. In: Lagrotta MGM, Ribeiro CPHA. A fonoaudiologia nas instituições. São Paulo: Lovise; 1997. p. 93-8.

8. Zorzi JL. A intervenção fonoaudiológica nas alterações da linguagem infantil. São Paulo: Revinter; 2002. 97p.

9. Serapompa MT. Avaliação da aprendizagem escolar. Rev CEFAC. 1999; 1(2):86-91.

10. Campiotto AR, Luz SR. Avaliação sobre as informações que o educador pré escolar possui frente aos aspectos fonoaudiológicos. Pró-Fono. 1996; 8(2):25-8.

11. Sant'Ana RB, Resende CA, Ramos LC. O interacionismo social e a investigação da brincadeira infantil: uma análise teórico-metodológica. Rev Bras Cresc Desenvolv Hum. 2004; 14(3):11-26.

RECEBIDO EM: 15/07/2007

ACEITO EM: 04/08/2008

Endereço para correspondência:

Rua Tirana, 150

Santo André - SP

CEP: 09241-090

Tel: (11) 4479-2377

E-mail: fonofatima@yahoo.com.br
12. Gomes ICD, Miranda LCM. Contribuições da comunicação alternativa de baixa tecnologia em paralisia cerebral sem comunicação oral: relato de caso. Rev CEFAC. 2004; 6(2):247-52.

13. Fujiki M, Spackman MP, Brinton B, Hall A. The relationship of language and emotion regulation skills to reticence in children with specific language impairment. J Speech Lang Hear. 2004; 47(3):637-46.

14. Pollonio CF. O brincar e a clínica fonoaudiológica. [dissertação] São Paulo (SP): Pontifícia Universidade Católica; 2005. p. 10-17

15. Bacha SMC, Osório AMN. Fonoaudiologia e educação: uma revisão da prática histórica. Rev CEFAC. 2004; 6(2):215-21.

16. Simões MS, Ferreira VJA. Avaliação de aspectos da intervenção fonoaudiológica junto a um sistema educacional. Rev CEFAC. 2002; 4(2):97-104.

17. Okano CB, Loureiro SR, Linhares MBM, Marturano EM. Crianças com dificuldades escolares atendidas em programa de suporte psicopedagógico na escola: avaliação do autoconceito. Psicol Reflex Crit. 2004; 17(1):121-8.

18. Rigolet SAN, Costa IMM. Estimulação precoce em comunicação e linguagem segundo o modelo V. O. E. [Fita de VHS]. Portugal: Pró-Fono Departamento Editorial; 1997.

19. Manolson A. It takes two to talk. A Hanen centre publication. The Beacon Herald Fine Printing Division. Canada: National Library of Canada; 1992. p.1-127.

20.Manolson A, Ward B, Dodington N. You make the difference. The Beacon Herald Fine Printing Division. Canada: National Library of Canada; 1995. p.1-90.

21. Pinto MCF. Programa Hanen para pais de crianças portadoras de retardo da linguagem. Reabilitar. 1999; 3(2):31-5.

22. Pinto MCF. Perfil dos pacientes e das famílias encaminhados ao programa Hanen. Rev CEFAC. 2003; 5(2):11-5.

23. Pinto MCF. Análise crítica dos motives apresentados por familiares para não freqüentar o programa Hanen numa instituição para deficientes físico. Rev CEFAC. 2003; 5(2):113-6.

24. Hart $\mathrm{KI}$, Fujiki $\mathrm{M}$, Brinton $\mathrm{B}$, Hart $\mathrm{CH}$. The relationship between social behavior and severity of language impairment. J Speech Lang Hear Res. 2004; 47(3):647-62.

25. Conti-Ramsden G, Botting N. Social difficulties and victimization in children with SLI at 11 years of age. J Speech Lang Hear Res. 2004; 47(1):145-61. 26. Howard JS, Sparkman CR, Cohen HG, Green G, Stanislaw H. A comparison of intensive behavior analytic and eclectic treatments for young children with autism. Res Dev Disabil. 2005; 26(4):359-83. 